\title{
ENSINO MÉDIO E EDUCAÇÃO FÍSICA: UM ESPAÇO DE SONHOS, RECEIOS E MANIFESTAÇÕES DAS CULTURAS JUVENIS
}

Lucas Silvestre dos Santos, Márcia Regina Canhoto de Lima.

Universidade Estadual Paulista - UNESP, Mestrado em Educação, Programa de Pós Graduação em Educação - PPGE, Presidente Prudente, SP. E-mail: lucassantos.educ@gmail.com. Financiamento: CAPES CNPq.

\section{RESUMO}

A juventude e suas manifestações tem ganhado cada vez mais espaço nas discussões acadêmicas. A situação conflituosa que se desvela entre os jovens alunos e a escola motivou o interesse por essa pesquisa, conhecer quem é o jovem que compõe a realidade escolar, quais seus sonhos e receios, bem como, se a educação física, pautada nos conteúdos da cultura corporal de movimento pode realizar um canal dialógico entre os sujeitos escolares, foram algumas das questões norteadoras. A pesquisa teve uma metodologia de natureza qualitativa de caráter do tipo etnográfica, utilizou como procedimentos para coleta de dados questionários semiestruturados, entrevistas e observação participante. Assim, observamos que a escola se mostrou um lugar riquíssimo em manifestações culturais e de uma dinamicidade ímpar, a aulas se mostraram um espaço eminentemente juvenil e isso possibilitou um compartilhar de vivências e experiências dos sujeitos.

Palavras - chave: Jovens Alunos, Ensino Médio, Educação Física, Culturas Juvenis, Cultura Corporal de Movimento.

\section{HIGH SCHOOL AND PHYSICAL EDUCATION: A PLACE OF DREAMS, FEARS AND MANIFESTATIONS OF YOUTH CULTURES.}

\begin{abstract}
Youth and its manifestations has gained more and more space in academic discussions. The conflictive situation that unfolds between the young students and the school led to the interest in this research, know who is the young man who composes the reality, what are your dreams and fears, as well as, physical education, based on the contents of the body culture movement can accomplish a Dialogic channel between school subjects, were some of the main issues. The survey had a qualitative methodology of the ethnographic type character, used as procedures for data collection questionnaires, semi-structured interviews and participant observation. Thus, we observe that the school showed a place rich in cultural events and an odd dynamic, the classes were an eminently juvenile space and this enabled a sharing of experiences and experiences of the subjects.
\end{abstract}

Keywords: young students, high school, physical education, youth cultures, body Culture movement.

\section{PREPAREM-SE PARA A VIAGEM: A INTRODUÇÃO}

$\mathrm{Na}$ contemporaneidade muito se tem falado sobre a juventude em suas manifestações. Pais (1990) pondera que esta é uma fase marcada por certa instabilidade. Ao refletirmos quanto à participação desses jovens no campo educacional, podemos perceber que essa instabilidade ocasiona conflitos, que Carrano (2009) descreve como uma situação de incomunicabilidade entre os sujeitos escolares.
Este cenário fluido e dotado de inúmeros contrastes e contradições se apresentou um campo motivador e interessante para a pesquisa. É necessário perceber que a juventude se desvela uma multifaceta cultural intensa. Na perspectiva educacional, temos que entender que antes de serem alunos, esses sujeitos são jovens, dotados de características próprias e formas de ver e se colocar no mundo (DAYRELL, 2007).

A pesquisa teve um caráter qualitativo, intentando, compreender e interpretar as 
culturas presentes no meio educacional. Assim, buscou conhecer quem são os sujeitos desse processo, seus sonhos e receios enquanto jovens alunos, e, se por intermédio dos conteúdos da cultura corporal de movimento é possível realizar um canal dialógico entre essas culturas.

\section{TODOS ABORDO: AS RELAÇÕES ENTRE AS CULTURAS JUVENIS E A ESCOLA.}

As escolas em sua grande maioria buscam alunos que permaneçam em silêncio e prontos para aprender os conteúdos. Será esse o único discente disposto a aprender? Esse modelo almejado está enraizado em muitas das instituições educacionais que desconsideram tudo que de certa forma seja uma "afronta" ao modelo instaurado.

Nossos jovens chegam à escola trazendo consigo uma imensa bagagem de experiências e vivências as quais entendemos que podem contribuir veementemente para o processo de aprendizagem. É nesse ponto da equação que o conflito surge. Afinal, temos dois pontos divergentes, a dinamicidade juvenil e a cultura escolar engessada.

Carrano (2005) pondera que é errôneo supor a existência de uma única cultura juvenil na escola. Além disso, não se deve também desconsiderar que as culturas são originárias do entorno escolar, sendo a instituição escola então, um local de expressão das culturas urbanas. Isto somado a nossa equação eleva a $n$ as possibilidades.

O autor (2005) ainda nos incita a refletir a respeito da seguinte situação: quando a escola age não reconhecendo o jovem-aluno como sujeito cultural, ela acaba por "se fechar em si mesma". Podemos assim dizer que tal postura contribui ainda mais para os desencontros no meio escolar.

Diante da demasia cultural presente nas escolas, faz sentido destinar um olhar cauteloso e atento aos jovens alunos, observando suas manifestações e relações para com a instituição e seus pares.

Martins e Carrano (2011) ensinam que a escola representa um local de culturas intercruzadas, espaços carregados de contradições. Semelhante característica é benéfica, afinal, torna os espaços escolares ricos culturalmente.

Dessa forma, entendemos a escola como um espaço "híbrido" (CANCLINI, 2000 p.19 apud MARTINS ; CARRANO, 2011, p. 46), ou seja, um local onde ocorrem grandes mesclas culturais. Essa hibridização se aproveitada como tal, pode ser uma verdadeira mina de ouro.

\section{AS CURVAS DO CAMINHO: METODOLOGIA}

$A$ pesquisa realizada foi possível mediante uma parceria firmada entre o CEPELIJ $^{1}$ e uma escola de ensino médio do Oeste paulista. A mesma foi pautada nos princípios éticos pertinentes a estudos com seres humanos e contou com registro número 22/2011 do Comitê de Ética em Pesquisa.

A metodologia foi de natureza qualitativa e caracterizou-se como pesquisa do tipo etnográfica. Esse tipo de metodologia faz um recorte da etnografia tradicional e realiza uma adaptação da mesma, o que a torna funcional nos assuntos pertinentes a educação (ANDRÉ, 2009).

Foram realizadas intervenções semanalmente, promovidas por bolsistas de iniciação à docência (PIBID), membros do mesmo grupo e matriculados no curso de licenciatura em educação física da FCT UNESP, acompanhados pela educadora da sala.

Os procedimentos de coleta de dados foram os questionários semiestruturados, entrevistas e a observação participante (ANDRÉ, 2009). Nessa metodologia o pesquisador se faz o instrumento mais importante para a coleta dos dados, pois se insere no meio intentando empregar um olhar de dentro, afinal, o objetivo não é quantificar as informações, mas sim, conhecer e interpretar a realidade e as características dos sujeitos (ALVES, 1991).

\section{PRIMEIRA ESTAÇÃO: RESULTADOS OBTIDOS}

Dentro dos espaços escolares, por vezes, os talentos juvenis passam despercebidos pela sociedade. Culturas essas, ricas e encantadoras. Falta à comunidade escolar parar um instante para ouvi-las, observá-las e conhece-las.

Um jovem apresentou, durante um diálogo em sala para o pesquisador, sua paixão pelos desenhos. Enquanto relatava, foi compartilhando algumas de suas obras. Reproduzia, e em alguns casos criava

\footnotetext{
${ }^{1}$ CEPELIJ- Centro de Estudos e Pesquisas em Educação, Ludicidade, Infância e Juventude. Este Centro tem sua sede no Prédio Discente III e busca congregar discentes e docentes universitários, professores da Educação Básica em atividades de estudo, investigação e pesquisa sobre conteúdos relativos à temática, nos mais diversos níveis de produção acadêmica: monografia, iniciação científica, pós-graduação lato-sensu e stricto-sensu e, ainda, atividades de extensão e ensino, desenvolvidas em espaços comunitários e instituições educacionais diversas.
} 
personagens de mangás. Seu talento era desconhecido pela professora da classe e até por alguns colegas.

Durante as intervenções os jovens-alunos foram expressando alguns de seus sonhos. bailarina"

Paula": "Um dos meus sonhos é virar

A jovem-aluna relatou esse desejo, durante uma atividade que trabalhava a flexibilidade. Segundo ela, desde pequena dança ballet e é muito apaixonada pelo que faz. Um de seus objetivos é ingressar na Faculdade de Dança, podendo assim, se aperfeiçoar mais.

As intervenções proporcionaram, também, a observação de uma aluna com D.I. (deficiência intelectual). A professora da sala relatou que apesar da deficiência a jovem-aluna era uma das mais participativas.

"Nina", realiza todas as atividades propostas, sendo respeitadas, suas limitações. (Relato da docente).

Para ela, a aula de Educação Física é um espaço de superação e socialização. Segundo a docente a educanda ficou com nota "dez" em sua disciplina, na concepção da educadora, mais importante que executar com perfeição o pedido é apresentar dedicação e comprometimento com o conteúdo. Atribuições que Nina têm de sobra. No entanto, a nota da jovem foi questionada pela direção. Que chegou insinuar que a professora teria dado nota por pena. A educadora, por sua vez, relatou sua indignação perante o ocorrido.

Professora: "Eu não tenho porque dar nota pra alguém. A 'Nina' tem suas limitações, mas, é uma aluna participativa e dedicada, ela mereceu a nota".

Em nossas observações, Nina sempre se mostrou uma aluna extremamente assídua. Buscando se envolver com as atividades e com os seus pares. A sua deficiência era perceptível, no entanto, a classe buscava inclui-la em todas as atividades. Talvez as aulas de Educação Física, fossem à forma mais prática da aluna se interagir com seus pares. Isso a levou a expressar certa vez:

"Eu gosto muito da Educação Física". (Relato de Nina)

A atmosfera de proximidade e camaradagem se constituía nas aulas de Educação Física, no entanto, no relato de alguns alunos nem sempre era possível fazer o mesmo

\footnotetext{
${ }^{2}$ Nome fictício.

${ }^{3}$ Alcunha referente uma personagem de novela que a garota gostava e pediu para ser chamada pelo pesquisador.
}

em outras aulas devido à "correria" do sistema educacional. A Educação Física, por sua vez, consolidava-se num espaço democrático, dinâmico, inclusivo e multicultural. Um espaço dos jovens e para os jovens.

Durante as entrevistas os discentes relatavam suas pretensões quanto a cursos superiores. Medicina, Arquitetura, Engenharia, Educação Física, Direito, Dança, Artes Cênicas, entre outros estiveram presentes nas opções dos jovens. Durante uma conversa uma jovem aluna expressou:

Cléia": "Eu quero fazer Direito, estudar bastante e passar num concurso da defensoria pública. Durante muito tempo eu quis ser juíza, mas mudei de ideia. Hoje quero ser advogada dos pobres mesmo".

Cristian": "Eu ainda não sei o que fazer, mas meus pais querem que eu faça faculdade".

O ensino médio se coloca como um espaço de sonhos e possibilidades, da mesma forma medos ou incertezas, um momento do "curso de vida" (PAIS, 1990) que para o jovem pode representar mudanças e escolhas que influirão no seu futuro. Além do mais, esse panorama envolve o querer próprio, a família e o que virá, assim, a sensação de calafrios é quase inevitável.

\section{SEGUINDO VIAGEM: DISCUSSÃO DOS RESULTADOS}

O que fazer quando terminar a escola? Faço o que quero ou o que meus pais dizem? Estudar ou trabalhar? Faculdade ou curso? Faço algo pra ganhar dinheiro ou algo que gosto? Essas são algumas perguntas que permeiam o mundo juvenil.

Vivemos em um sistema de sociedade, no qual, muitas vezes precisamos optar entre os sonhos e as necessidades, isso cerra em si potencialidades imensuráveis. No desvelar dessa pesquisa vimos uma juventude repleta de sonhos e peculiaridades, potencialidades em diversos aspectos, que no final do ciclo escolar terão de ser colocados na balança, seus desejos ou suas precisões. Dessa forma, por inúmeros motivos, nem todos podem vivenciar suas condições juvenis (DAYRELL, 2007).

É perceptível na fala dos alunos, que, por mais que anseie um curso superior, à certeza quanto que curso fazer ainda não existe para a 
grande maioria. Alguns jovens relataram que sentem uma imensa pressão quanto o assunto universidade. Afinal, a escolha da graduação culmina numa decisão importantíssima para sua vida.

Como a sociologia aponta, a juventude é vista como um curso de vida, assim, escolher o que pode vir a ser sua profissão no mundo adulto é uma tarefa assustadora. No entanto, uma coisa é certa, se no percurso o jovem reconhecer àquela escolha como errada ele não tem o mínimo de receio de voltar e tentar novamente. Pais (2009) nos apresenta essa situação com a metáfora da geração iô iô. Tal certeza transmite um pouco de tranquilidade para o jovem. Afinal, ele sabe que esse momento não determina o fim, mas sim o começo de uma nova etapa da sua construção identitária juvenil.

\section{ULTIMA PARADA: A CONCLUSÃO}

A pesquisa ampliou nossos horizontes intelectuais, não só como pesquisadores, mas, e, sobretudo, como seres humanos. Percebemos que a escola pode sim ser um espaço de multifacetas culturais.

A disciplina de Educação Física pôde realizar um diálogo integrativo com as culturas juvenis no meio escolar. E também se apresentar como um espaço eminentemente juvenil. Afinal, na constante busca pela compreensão do universo juvenil, abriram-se caminhos para a interlocução entre o vivido pelos jovens no seu cotidiano e a prática efetivada nas aulas.

As relações juvenis são intensas e constantes. A escola é um ambiente riquíssimo, no qual, essas culturas estão em constantes processos de construção e desconstrução. Nessas aulas, os jovens criam espaços de interações com seus semelhantes, nos quais, as trocas culturais e uma apresentação do seu ser pessoal são inestimáveis.

A valorização dos signos e significados dos sujeitos, respeitando seus limites propõe um ambiente de superação e valorização mútua, fortalecendo os elos e possibilitando as trocas interculturais.

A Cultura Corporal de Movimento, como elemento do currículo se desvela como um leque de possibilidades, proporcionando um diálogo entre os sujeitos presentes no processo educativo. Tal situação contribui para a ressignificação do espaço escolar, proporcionando uma maior representatividade do mesmo, bem como, o tornando mais prazeroso e dotado de sentido, permitindo ao jovem-aluno considerar aquele espaço como seu.

\section{REFERÊNCIAS}

ALVES, A. J. O planejamento de pesquisas qualitativas em educação. Cadernos de Pesquisa, São Paulo, v. 77, p. 53-61, maio 1991.

ANDRÉ, M. E. D. A. Etnografia da prática escolar. 16.ed. Campinas, SP: Papirus, 2009.

CARRANO, P. Construção coletiva: contribuições à educação de jovens e adultos. Brasília:

[UNESCO], p.153-163, ago. 2005. v.3.

CARRANO, P. Identidades culturais juvenis e escolas: arenas de conflitos e possibilidades.

Diversia, n.1, p. 159-184, abr. 2009.

DAYRELL, J. "A escola 'faz' as juventudes?

Reflexões em torno da socialização juvenil".

Educação e Sociedade, Campinas, v.28, n.100, p. 1105-1128, out. 2007.

https://doi.org/10.1590/S0101-

73302007000300022

MARTINS, C.; CARRANO, P. A escola diante das culturas juvenis: reconhecer para dialogar.

Educação, Santa Maria, v. 36, n. 1, p. 43-56, jan./abr. 2011.

https://doi.org/10.5902/198464442910

PAIS, J. M. A construção sociológica da juventude: alguns contributos. Análise Social, v. 25, n.105106, p. 139-165, 1990.

PAIS, J. M. Juventude como fase de vida: dos ritos de passagem aos ritos de impasse. Saúde Soc., São Paulo, v.18, n.3, p. 371-381, 2009.

Recebido para publicação em 23/08/2016

Revisado em 23/08/2016

Aceito em 29/08/2016 